\title{
Simultaneous removal of nutrients in a novel anaerobic-anoxic/ aerobic sequencing reactor: removal of nutrients in a novel reactor
}

\author{
A. Azhdarpoor ${ }^{1} \cdot$ P. Mohammadi $^{2} \cdot$ M. Dehghani ${ }^{1}$
}

Received: 1 August 2014/Revised: 1 July 2015/ Accepted: 14 July 2015/Published online: 4 August 2015

(C) Islamic Azad University (IAU) 2015

\begin{abstract}
Discharging wastewater contaminated with nitrogen and phosphorus compounds (nutrients) can be harmful to both human health and the environment. The present study investigated the efficiency of removing total nitrogen, total phosphate, and chemical oxygen demand using a novel reactor design. The reactor was an anaerobic-anoxic/aerobic sequencing batch reactor with continuous influent and discontinuous outlet. The operation consisted of four phases. Phases 3 and 4 had mixing cycles, whereas phases 1 and 2 only had aeration, settling, and discharge cycles. Phase 4 was the most effective. The average removal efficiencies for chemical oxygen demand, $\mathrm{NH}_{4}^{+}$, total nitrogen, and total phosphate in Phase 4 were $92,91,86$, and $85 \%$, respectively. This phase comprised $225 \mathrm{~min}$ of intermittent aeration time, $165 \mathrm{~min}$ of intermittent mixing time, and 90 min of settling and discharge. In addition to high efficiency in nutrient removal, the reactor had other advantages, including continuous flow and performance in all phases.
\end{abstract}

Keywords Nitrogen $\cdot$ Phosphate $\cdot$ Sequencing batch reactor $\cdot$ Wastewater

Electronic supplementary material The online version of this article (doi:10.1007/s13762-015-0871-5) contains supplementary material, which is available to authorized users.

A. Azhdarpoor

azhdarpoor@sums.ac.ir

1 Department of Environmental Health, School of Health, Shiraz University of Medical Sciences, Shiraz, Iran

2 Environmental Health Engineering, Shiraz University of Medical Sciences, Shiraz, Iran

\section{Introduction}

The discharge of wastewater contaminated with nitrogen and phosphorus compounds (nutrients) as a result of human activities can have harmful effects on human health and the environment. Excessive nutrients in water bodies can cause a variety of problems, including reduced oxygen concentration in water, which can lead to fish death, eutrophication, and over-fertilization. Eutrophication is associated with a range of water quality issues such as increased water treatment costs, reduced recreation quality, and the production of algal toxins with potentially lethal effects on humans (Falkowski et al. 2000; Morse et al. 1998; Renman et al. 2008).

A variety of physicochemical, chemical, and biological methods have been used to remove nutrients from wastewater. Phosphorus removal is possible by physicochemical methods (deposition using materials such as alum, lime, and iron salts) and biological methods (Phostrip, Bardenpho, A/O) (Morse et al. 1998). Removal of nitrogen compounds from wastewater has been performed through physical methods (reverse osmosis, air stripping), chemical methods (ion exchange, breakpoint chlorination), and biological methods (nitrification-denitrification) (Renman et al. 2008). Among these approaches, biological nutrient removal has been considered the most economical and efficient method of wastewater treatment ( $\mathrm{Li}$ and Irvin 2007; Sibag and Kim 2012; Yuan et al. 2012).

Biological nitrogen removal involves two processes, namely nitrification and denitrification, whose final product is nitrogen gas. First, nitrification is performed by autotrophic microorganisms in aerobic conditions. Then, denitrification is performed in anoxic conditions by heterotrophic microorganisms (Fu et al. 2009a, b; Wei et al. 2012; Wu et al. 2014). In the anaerobic phase, phosphate- 
accumulating organisms (PAOs) sequester organic substances, especially volatile fatty acids (VFAs), in their cells as polyhydroxyalkanoates (PHAs). In the aerobic phase, PHA acts as an energy source for the uptake of phosphate from solution. Finally, the phosphate-rich sludge is discharged from the treatment system. Phosphate adsorption above cellular capacity by PAOs is possible in enhanced biological phosphorus removal (EBPR). EBPR places the PAOs in alternating anaerobic and aerobic conditions (Zhou et al. 2012; Drewnowski and Makinia 2014). Simultaneous removal of total phosphate (TP) and total nitrogen (TN) consumes organic matter. However, the chemical oxygen demand (COD) of the denitrifier microorganisms leads to problems in the EBPR process because it reduces the efficiency of the PAOs in the uptake and storage of the organic substances needed for absorption of the phosphate. The formation of nitrate by the microorganisms in the aerobic phases and its presence in the anaerobic phases blocks phosphate release by the PAOs. A sequencing batch reactor (SBR) allows control of the environment in terms of electron receptors (oxygen or nitrate) and is therefore a good option for nutrient removal. Its benefits include control of oxygen levels and redox conditions, use of aerobic and anaerobic cycles, and low operating costs (Fu et al. 2009b). The SBR process has been widely used for simultaneous removal of COD and nutrients (Azhdarpoor et al. 2014; Aslan and Kapdan 2006; Cui et al. 2014). In general, simultaneous removal of nutrients in a single reactor is advantageous because it avoids operational complexities (Park et al. 2009; Wei et al. 2012). As noted, to remove both nitrogen and phosphorus compounds, alternating anaerobic and aerobic conditions are required, which are present in the SBR process. However, disruptions caused by denitrifiers have required many refinements to SBR systems (Fu et al. 2009b). The reactor system used in this study was designed to tackle this. The study aimed to investigate the simultaneous removal of nutrients (TN and TP) and COD from wastewater using a novel anaerobic-anoxic/aerobic SBR. The advantages of this modified anaerobic/aerobic SBR reactor include high efficiency and inclusion of anaerobic and aerobic tanks in a single reactor, thus reducing the space needed. Also, unlike conventional SBR reactors, the influent is continuous and upward moving. The research was carried out at the main environmental sciences laboratory of Shiraz University of Medical Sciences.

\section{Materials and methods}

\section{Operational phases}

This study consisted of four phases. In phases 1 and 2, aeration and settling cycles were used, while phases 3 and 4 used alternating aeration, mixing, and settling cycles. Phases 1, 2, 3, and 4 were run for 180, 240, 360, and $480 \mathrm{~min}$, respectively. Details of the operational phases are presented in Fig. 1.

\section{Synthetic wastewater}

Synthetic wastewater was used to avoid fluctuations in the amounts of COD, ammonia, and phosphate in the influent and to maintain control over the reactor system (Rahimi et al. 2011). The minimum and maximum inlet concentrations were 250 and $1500 \mathrm{mg} / \mathrm{l} \mathrm{COD,} 4$ and $61 \mathrm{mg} / \mathrm{l} \mathrm{TP}$, and 40 and $100 \mathrm{mg} / \mathrm{l}$ ammonia. The $\mathrm{pH}$ level of the inlet wastewater was approximately 7.4. The water required to produce the synthetic wastewater was taken from the urban water supply network. The materials and values used to produce the synthetic wastewater are shown in Table 1.

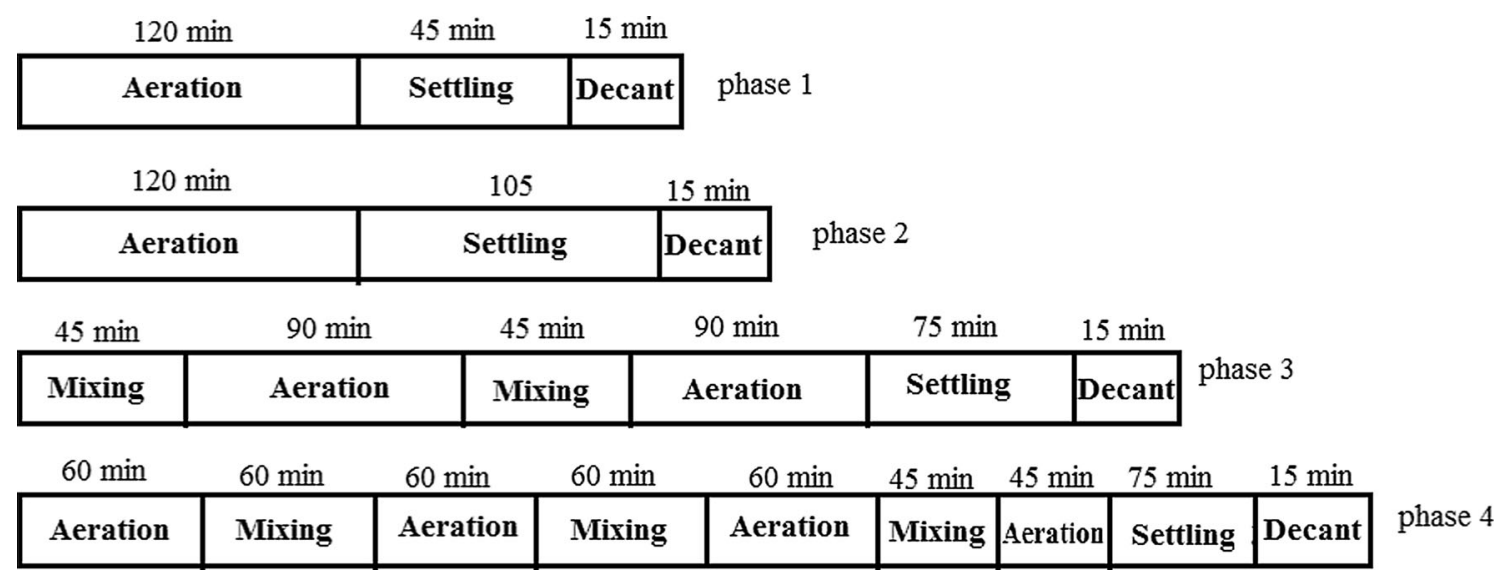

Fig. 1 Four operational phases in an anaerobic-anoxic/aerobic sequencing batch reactor 
Table 1 Characteristics of the influent to the reactor

\begin{tabular}{ll}
\hline Material & Concentration $(\mathrm{g} / \mathrm{l})$ \\
\hline Glucose & $0.33-0.97$ \\
Sucrose & $0.12-0.36$ \\
Sodium acetate & $0.12-0.36$ \\
$\mathrm{KH}_{2} \mathrm{PO}_{4}$ & $0.011-0.84$ \\
$\mathrm{NH}_{4} \mathrm{Cl}$ & $0.14-0.39$ \\
$\mathrm{Trace} \mathrm{elements}(\mathrm{mg} / \mathrm{l})_{2}$ & \\
$\mathrm{ZnSO}_{4}$ & 0.45 \\
$\mathrm{FeCl}_{3}$ & 0.1 \\
$\mathrm{Na}_{2} \mathrm{MoO}_{4}$ & 0.8 \\
$\mathrm{CoCl}_{2}$ & 0.4 \\
$\mathrm{CuSO}_{4}$ & 0.4 \\
$\mathrm{NiCl}_{2}$ & 0.2 \\
$\mathrm{MnCl}_{2}$ & 0.28 \\
\hline
\end{tabular}

\section{Reactor description}

A modified form of SBR was used in this study. The synthetic wastewater entered the reactor continuously in an upward flow, and the effluent was discharged discontinuously. The reactor consisted of two parts. The first part was permanently anaerobic. The second part, which was anoxic/aerobic, was separated by a Plexiglas sheet from the anaerobic part. These conditions were maintained by aeration and the use of an electric timer. To achieve mixing in the absence of aeration in the anoxic/aerobic phases 3 and 4 , a mixer was used with the engine speed kept constant at
$50 \mathrm{rpm}$. The reactor had an internal diameter of $15 \mathrm{~cm}$ and a height of $40 \mathrm{~cm}$. The total reactor volume was 91 and the working volume ranged from 51 in Phase 1 to 71 in the Phase 4. A schematic presentation of the reactor and its accessories is shown in Fig. 2.

\section{Reactor operation}

First, return sludge from the aeration tank of the wastewater treatment plant of Shiraz, Iran, was used for microbial seeding of the system. No samples were taken during the first 14 days of the study, to allow the microorganisms to adapt to conditions different from those of the treatment plant. The duration of reactor operation was 150 days. The concentration of dissolved oxygen (DO) was about $3 \mathrm{mg} / \mathrm{l}$ in the aerobic cycle, around $0-0.2 \mathrm{mg} / \mathrm{l}$ in the mixing cycle, and $0 \mathrm{mg} / \mathrm{l}$ in the settling cycle. A DO meter (HQd Field Case, Hach, USA) was used to measure DO, and a pH meter (Metrohm model 826, Switzerland) was used to measure $\mathrm{pH}$. For controlling aeration, mixing, and discharge, three electric timers (Theben-Germany) were used. A solenoid valve (2\&2, China) was used for discontinuous discharge of the supernatant. Finally, an aquarium air pump was used for aeration of the system (Leviton, USA).

\section{Testing methods}

COD was measured following standard methods (APHA 1999). A spectrophotometer (model DR-5000, Hach) was used to measure $\mathrm{TP}$, ammonium $\left(\mathrm{NH}_{4}{ }^{+}\right)$, nitrate $\left(\mathrm{NO}_{3}{ }^{-}\right)$,

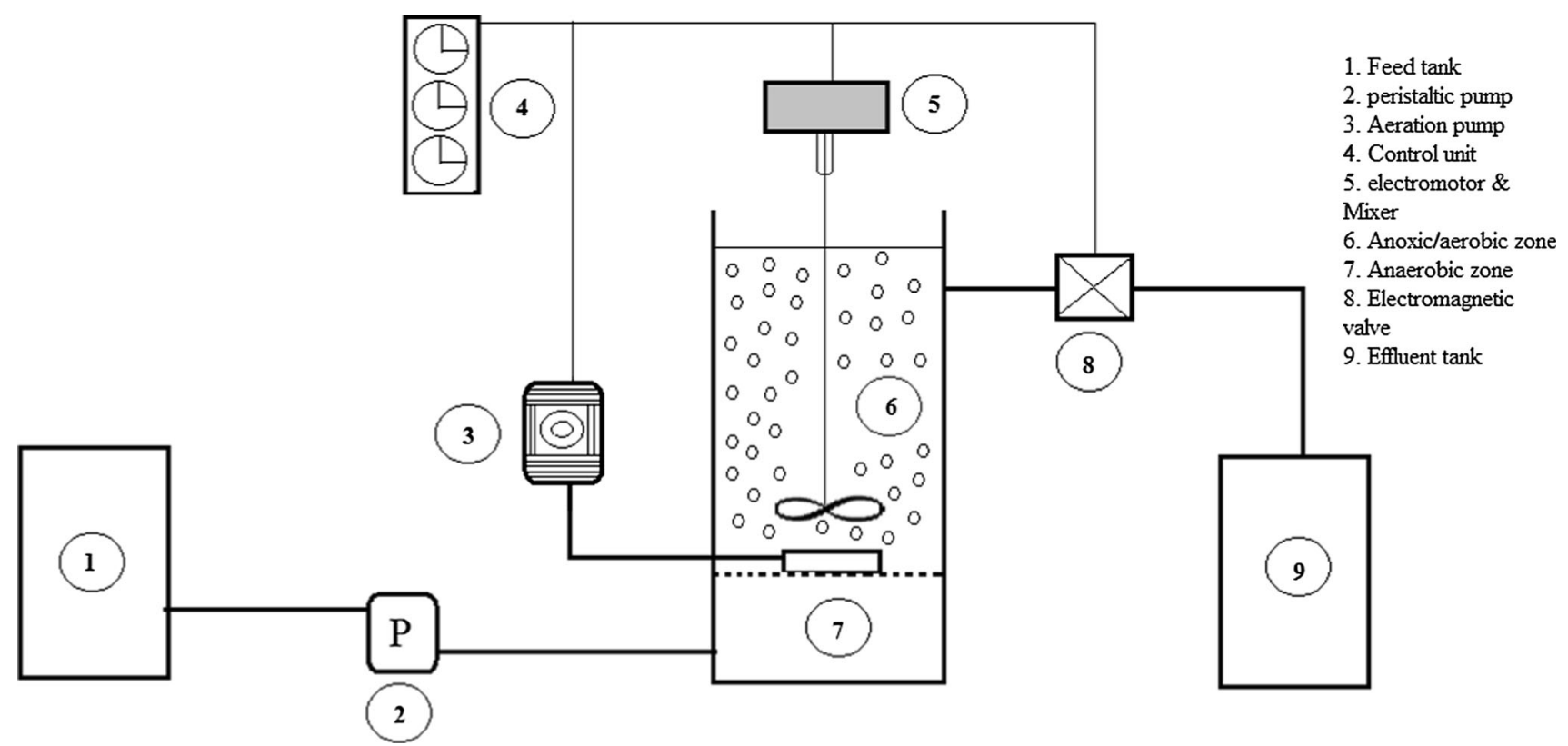

Fig. 2 Schematic presentation of a novel anaerobic-anoxic/aerobic sequencing batch reactor and its accessories 
Fig. 3 Input COD removal in four phases of an anaerobicanoxic/aerobic sequencing batch reactor

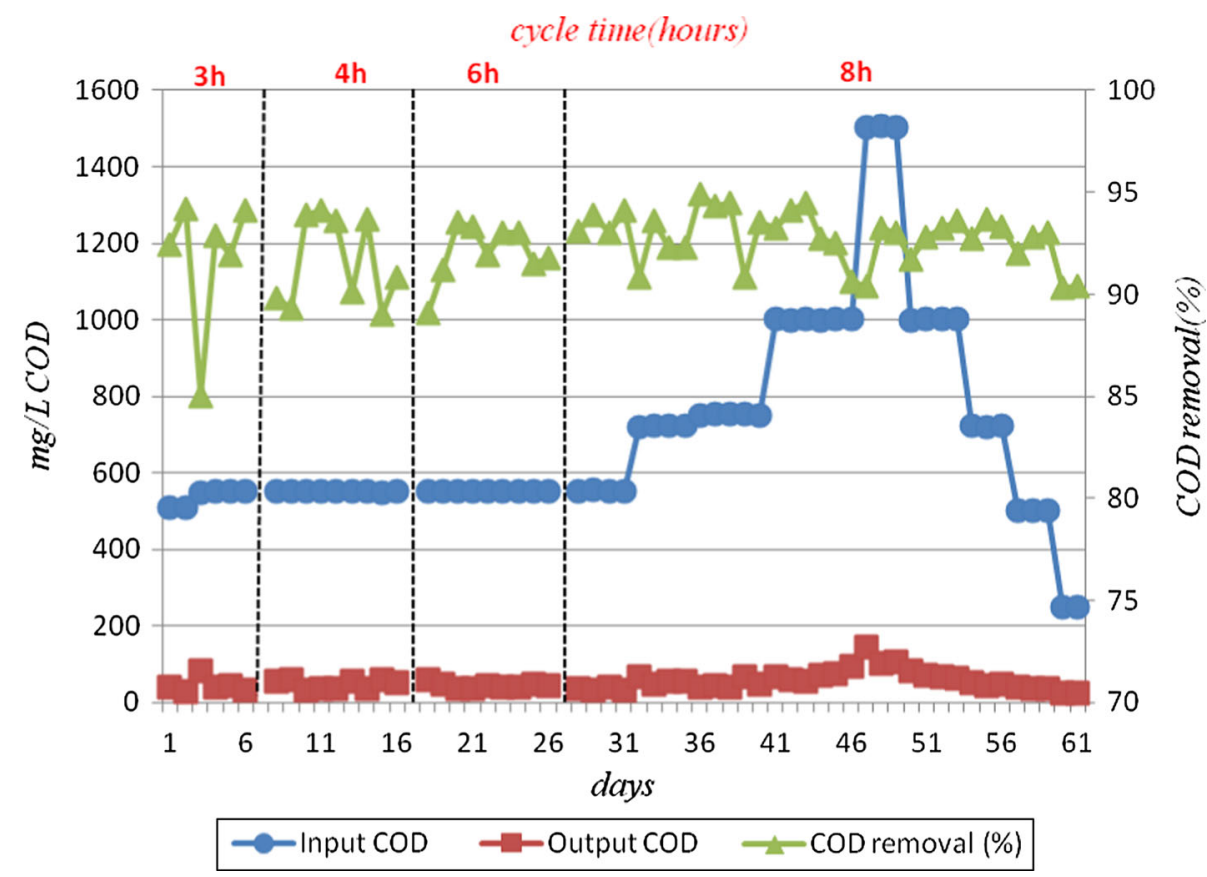

and nitrite $\left(\mathrm{NO}_{2}{ }^{-}\right)$. In the measurement of TP using the ascorbic acid method (No. 8048), orthophosphate in the sample reacts with molybdate in an acidic medium and a complex is formed. Ascorbic acid reduces this complex, and a blue color is created, the intensity of which represents the amount of orthophosphate in the sample. The measurement wavelength is $880 \mathrm{~nm}$ for spectrophotometry. In the measurement of ammonia by the Nessler method (No. 8038), polyvinyl alcohol (as dispersing agent) produces a yellow color during the reaction of the Nessler reagent with ammonia and certain other amines. This can be detected at a wavelength of $425 \mathrm{~nm}$. In the measurement of nitrate by the cadmium reduction method (No. 8039), metal cadmium converts the nitrate in the sample into nitrite. Nitrite ions in the sulfanilic acidic medium react to form diazonium salt. The salt then reacts with gentisic acid, and an amber solution is formed. This can be detected at a wavelength of $520 \mathrm{~nm}$. In nitrite measurement by the USEPA Diazotization Method (No. 8507), the nitrite present in the sample reacts with sulfanilic acid and a diazonium salt is formed. This salt reacts with chromotropic acid, and a pink complex is formed which can be detected at a wavelength of $507 \mathrm{~nm}$ (Wang et al. 2010). All the experimental reagents used in the present study were of analytical grade. The average values of the data obtained under steady state conditions were used for further calculations (at 5-7 days for each concentration).

\section{Results and discussion}

\section{COD removal}

COD removal efficiency was high in all phases, and no significant differences were observed between different phases (Fig. 3). Phases 1, 2, and 3 had inlet COD values of $550 \mathrm{mg} / \mathrm{l}$, and none could be considered more efficient than the others. Phase 4 , with COD concentrations up to $1500 \mathrm{mg} / \mathrm{l}$, was superior to the other phases. Figure 3 shows that there was very little fluctuation in the removal efficiency curve as COD increased; a constant smooth reduction was observed to the end of the phase. This suggests that the reactor had a tolerance for high levels of COD and COD shock loading. The average COD removal efficiency was $91.7,91.5,92$, and $92.7 \%$ in phases 1,2 , 3 , and 4, respectively. Most nutrient removal systems are effective in reducing COD, because organic materials are necessary in nutrient removal processes and much of the COD takes place in anaerobic conditions (Fu et al. 2009a; Chae and Shin 2007). In systems for simultaneous removal of nutrients and COD, a large amount of COD is consumed by the denitrifiers and PAOs. Fu et al. 2009a investigated simultaneous nitrogen and phosphorus removal using a novel sequencing batch moving bed membrane bioreactor (SBMBMBR). At inlet COD concentration of $500 \mathrm{mg} / \mathrm{l}$, they found an average COD removal efficiency of $93.5 \%$ ( $F u$ et al. 2009a). In our 
Fig. 4 Ammonia removal in four phases of an anaerobicanoxic/aerobic sequencing batch reactor cvcle time(hours)

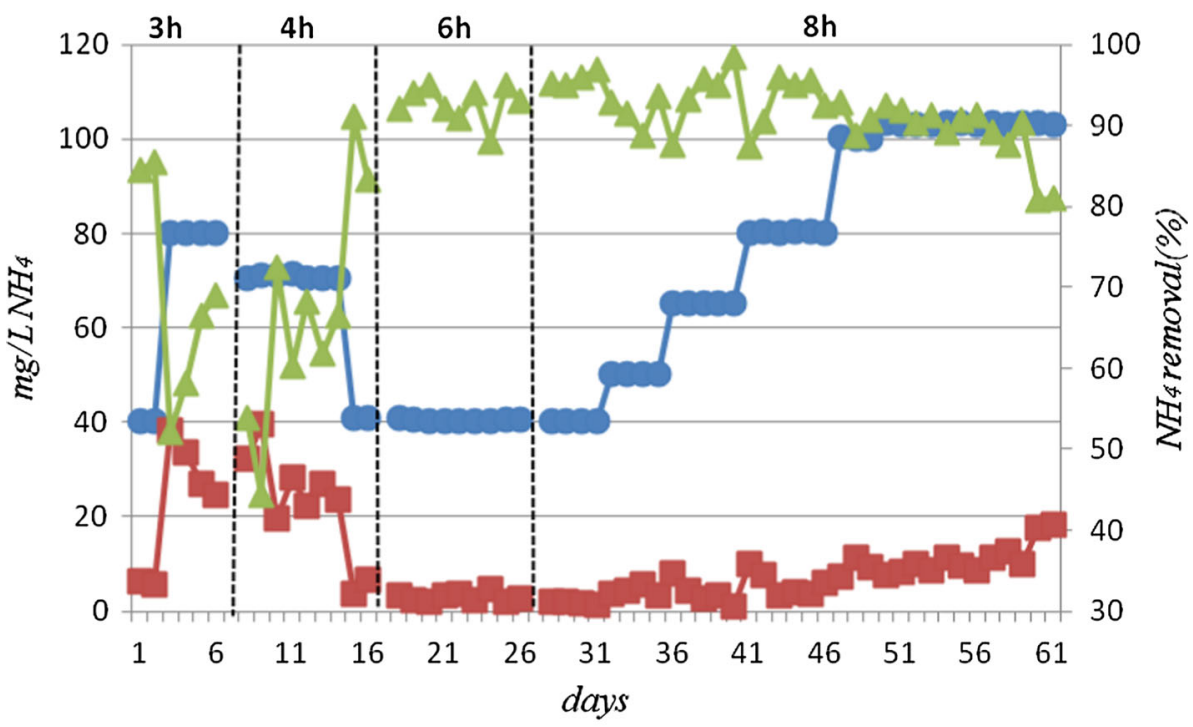

- Input Ammonium $\rightarrow$ Output Ammonium $\rightarrow$ Ammonium removal (\%) reactor, $91.9 \%$ COD removal was achieved without using a membrane module.

\section{Removal of nitrogen compounds}

To remove ammonia, two stages of aerobic nitrification and anoxic denitrification are required. Oxygen concentrations reported in different studies range from 2 to $5 \mathrm{mg} / \mathrm{l}$ in the first stage and are below $0.3 \mathrm{mg} / \mathrm{l}$ in the second ( $\mathrm{Hu}$ et al. 2010) (Fig. 4). In the current study, the value was 3.5 in aeration conditions, falling to near zero in anoxic conditions. Moreover, according to Luostarinen et al. (2006), anaerobic pretreatment produces compounds capable of further decomposition, which are useful for biological removal of nitrogen compounds. Our reactor also demonstrated this advantage. With an input of $40 \mathrm{mg} / \mathrm{l}$ ammonia at the beginning of Phase 1, a removal efficiency of $85 \%$ was observed. As the input concentration increased to $80 \mathrm{mg} / \mathrm{l} \mathrm{NH}_{4}{ }^{+}$, this efficiency fell to $61 \%$, showing that Phase 1 had peak efficiency at inlet concentrations of $40 \mathrm{mg} / \mathrm{NH}_{4}{ }^{+}$. Similar results can be seen in Fig. 5 for TN removal. Nitrate output was initially at about $14 \mathrm{mg} / \mathrm{l}$ and then increased to $26 \mathrm{mg} / \mathrm{l}$. Similarly, nitrite was initially $0.87 \mathrm{mg} / \mathrm{l}$, increasing to $8.3 \mathrm{mg} / \mathrm{l}$. In Phase 2 , fluctuations were observed in $\mathrm{NH}_{4}{ }^{+}$and TN removal efficiency at inlet ammonia concentrations of $70 \mathrm{mg} / \mathrm{l}$. The average removal efficiency reached $61 \%$ for $\mathrm{NH}_{4}{ }^{+}$and $52 \%$ for TN. The average concentration of output nitrate and nitrite was 16 and $5 \mathrm{mg} / \mathrm{l}$, respectively. However, the concentration of input $\mathrm{NH}_{4}{ }^{+}$was $40 \mathrm{mg} / \mathrm{l}$, a higher removal efficiency than in Phase 1 (approximately $90 \%$ ). At this concentration,
TN removal efficiency was above $52 \%$ and output nitrate and nitrite concentrations were 8.5 and $12 \mathrm{mg} / \mathrm{l}$, respectively. In their study on the efficiency of biological nutrient removal in an SBR, Kargi and Uygur found that shorter anoxic/aerobic periods led to better nutrient removal efficiency (Kargi and Uygur 2003). Freitas studied the effect of short SBR cycles on nutrient removal and found many advantages of short cycles, including increased efficiency of nutrient removal, improved SBR process performance, reduced energy consumption, and increased richness of anaerobic and aerobic microbes (Freitas et al. 2009). In a study of nitrogen and phosphorus removal from abattoir wastewater in an SBR with aerobic granular sludge, shorter settlement cycles in the SBR process were found to improve waste removal (Cassidy and Belia 2005). In the present study, Phase 3 coincided with the entry into operation of the reactor and the use of short anoxic/aerobic cycles with a shorter settling time. During this phase, $\mathrm{NH}_{4}{ }^{+}$ removal efficiency remained at $90 \% \pm 2$. This consistency was also observed for TN removal efficiency. In Phase 3, the average TN removal efficiency was $71 \%$ and the amounts of nitrate and nitrite discharged from the reactor were 21 and $6.5 \mathrm{mg} / \mathrm{l}$, respectively. Phases 2 and 3 were similar in terms of $\mathrm{NH}_{4}{ }^{+}$input $(40 \mathrm{mg} / \mathrm{l})$. However, Phase 3 had higher efficiency and its curve showed smaller fluctuations. Thus, Phase 3 was superior to Phase 2 in this regard. TN removal efficiency was $52 \%$ in Phase 2 and $71 \%$ in Phase 3 . The beginning of Phase 4 was similar to Phase 3 in terms of $\mathrm{NH}_{4}^{+}$input $(40 \mathrm{mg} / \mathrm{l})$ with shorter cycles. Yet the average removal efficiency of $\mathrm{NH}_{4}{ }^{+}$in Phase 4 was slightly higher (95\%). TN removal efficiency 
Fig. 5 Total nitrogen (TN) removal efficiency and nitrate and nitrite production in four phases of an anaerobic-anoxic/ aerobic sequencing batch reactor

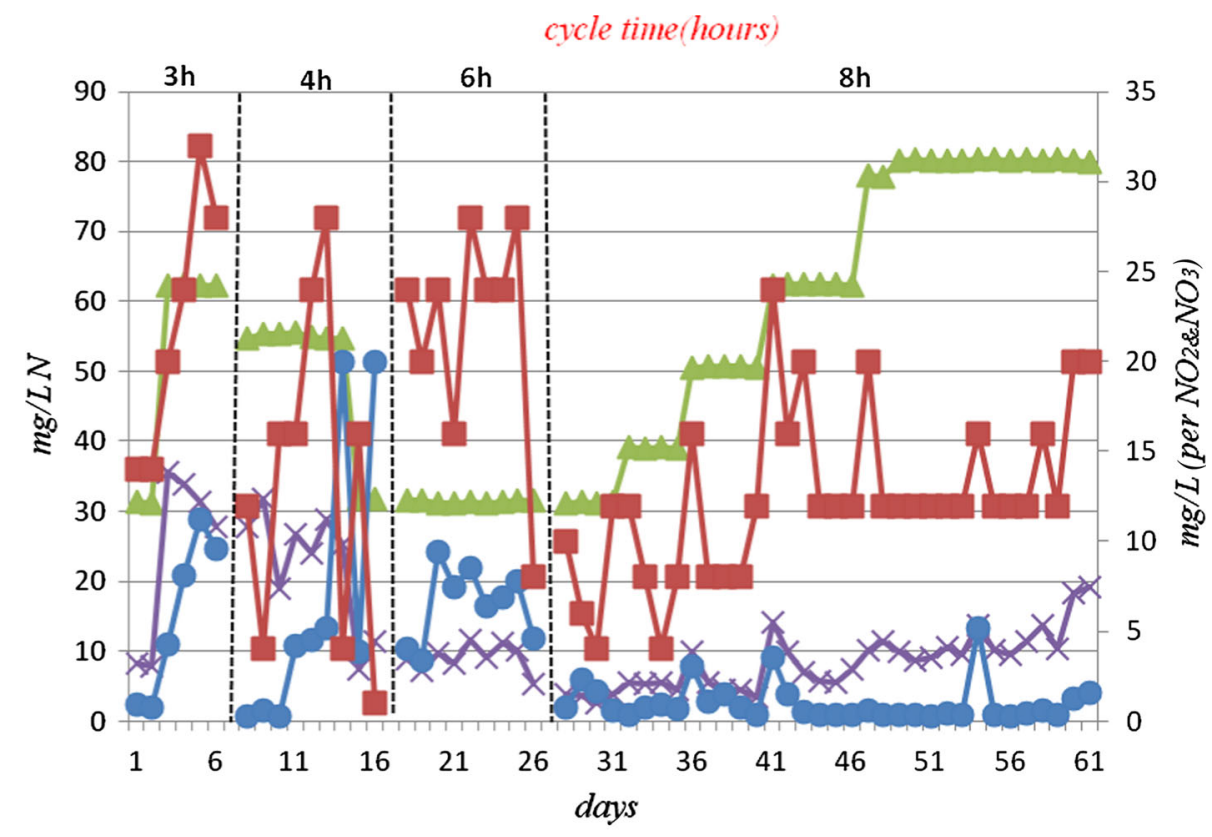

$\leadsto$ Input TN $\asymp$ Output TN $\frown$ Output nitrite $\leftrightharpoons$ Output nitrate was $88.5 \%$, which is consistent with the results of a study by Li et al. (2012) on simultaneous removal of carbon and nitrogen in a circulating fluidized bed biofilm reactor (CFBBR). The study found that over $85 \%$ of TN was removed during slow bioparticle circulation between Riser (Anoxic) and Downer (Aerobic) with $350 \mathrm{mg} / \mathrm{l} \mathrm{COD}$ and $40 \mathrm{mg} / \mathrm{l} \mathrm{NH}_{4}{ }^{+}$. Our reactor achieved similar efficiency levels without return sludge in terms of the amount of $\mathrm{NH}_{4}{ }^{+}$input and COD (500 mg/l). Phase 4 was more efficient than Phase 3 in terms of TN removal; the amount of nitrate and nitrite discharged initially were 8 and $0.2-1.5 \mathrm{mg} / \mathrm{l}$, respectively. In this phase, the amount of input $\mathrm{NH}_{4}{ }^{+}$increased from 50 to $80 \mathrm{mg} / \mathrm{l}$ and COD increased from 720 to $1000 \mathrm{mg} / \mathrm{l}$. The amount of input $\mathrm{NH}_{4}{ }^{+}$and COD increased and $\mathrm{NH}_{4}{ }^{+}$and $\mathrm{TN}$ removal efficiency increased to 93 and $87.7 \%$, respectively, in a stepwise manner. The amounts of output nitrate and nitrite were 12 and $1 \mathrm{mg} / \mathrm{l}$, respectively. When holding $\mathrm{NH}_{4}{ }^{+}$ constant at $100 \pm 2 \mathrm{mg} / \mathrm{l}$ and increasing the input COD to $1500 \mathrm{mg} / 1, \mathrm{NH}_{4}{ }^{+}$and TN removal efficiencies reached 91 and $86.5 \%$, respectively, while output nitrate and nitrite reached 14 and $0.44 \mathrm{mg} / \mathrm{l}$. However, with consolidation of $\mathrm{NH}_{4}{ }^{+}$, the input COD value reduced from 1500 to $250 \mathrm{mg} /$ $1(\mathrm{C} / \mathrm{N}=3.1-19)$. In other words, the reactor's performance was tested in the absence of carbon input for reducing the levels of $\mathrm{NH}_{4}{ }^{+} . \mathrm{NH}_{4}{ }^{+}$and $\mathrm{TN}$ removal efficiencies remained at 90 and $87 \%$, respectively, up to an input COD of $500 \mathrm{mg} / \mathrm{l}$, while output nitrate and nitrite levels were 12.8 and $0.8 \mathrm{mg} / \mathrm{l}$, respectively. At an input COD of $250 \mathrm{mg} / \mathrm{l}, \mathrm{NH}_{4}{ }^{+}$and $\mathrm{TN}$ removal efficiency reached 81 and $77 \%$, respectively, and nitrate and nitrite output reached 20 and $1.3 \mathrm{mg} / \mathrm{l}$, respectively. This suggested that $\mathrm{NH}_{4}{ }^{+}$removal efficiency in this phase was not significantly related to the input ammonia/carbon ratio. The highest removal efficiency $(86.5 \%)$ was recorded at a $\mathrm{C} / \mathrm{N}$ ratio of 19 . When the $\mathrm{C} / \mathrm{N}$ ratio was reduced to $12.4, \mathrm{NH}_{4}{ }^{+}$ removal efficiency fell to $80 \%$. The lowest ratio of $\mathrm{C} / \mathrm{N}$ was 3.1 , corresponding to an $\mathrm{NH}_{4}{ }^{+}$removal efficiency of $80 \%$. The input COD removal efficiency did not change as input $\mathrm{C} / \mathrm{N}$ ratios were reduced. Using real-time control with step-feed SBR technology, Guo reported that at a $\mathrm{C} / \mathrm{N}$ ratio of 3.5, an input $\mathrm{NH}_{4}{ }^{+}$concentration of $40-60 \mathrm{mg} / \mathrm{l}$, and a COD input of $180-220 \mathrm{mg} / \mathrm{l}$, TN removal efficiency reached $98 \%$ (Guo et al. 2007). In our reactor, with continuous feeding and a $\mathrm{C} / \mathrm{N}$ ratio of 19 (with an input COD of $1500 \mathrm{mg} / \mathrm{l}$ and $\mathrm{NH}_{4}^{+}$of $100 \mathrm{mg} / \mathrm{l}$ ), TN removal efficiency was $86.5 \%$.

\section{Removal of total phosphate}

Because PAOs tend to use organic materials with low molecular weight, the anaerobic area at the beginning of the process plays a selective role in breeding PAOs (Metcalf and Eddy 2003). In phases 1 and 2, and at TP concentration of $8-16 \mathrm{mg} / \mathrm{l}$, the removal efficiency was 58.1 and $84.5 \%$, respectively. In Phase 3, the value was $83.9 \%$ at a concentration of $8 \mathrm{mg} / \mathrm{l}$, and in Phase 4 , it was $84.6 \%$ at a concentration of $8-60 \mathrm{mg} / \mathrm{l}$. At entry levels of $8 \mathrm{mg} / \mathrm{l}$ TP in Phase 1 , the removal efficiency was approximately $70 \%$ (Fig. 6). However, when the input TP was doubled, the removal efficiency reduced to approximately $50 \%$. This shows the inefficiency of Phase 1, which can be 
Fig. 6 TP removal in four phases of an anaerobic-anoxic/ aerobic sequencing batch reactor

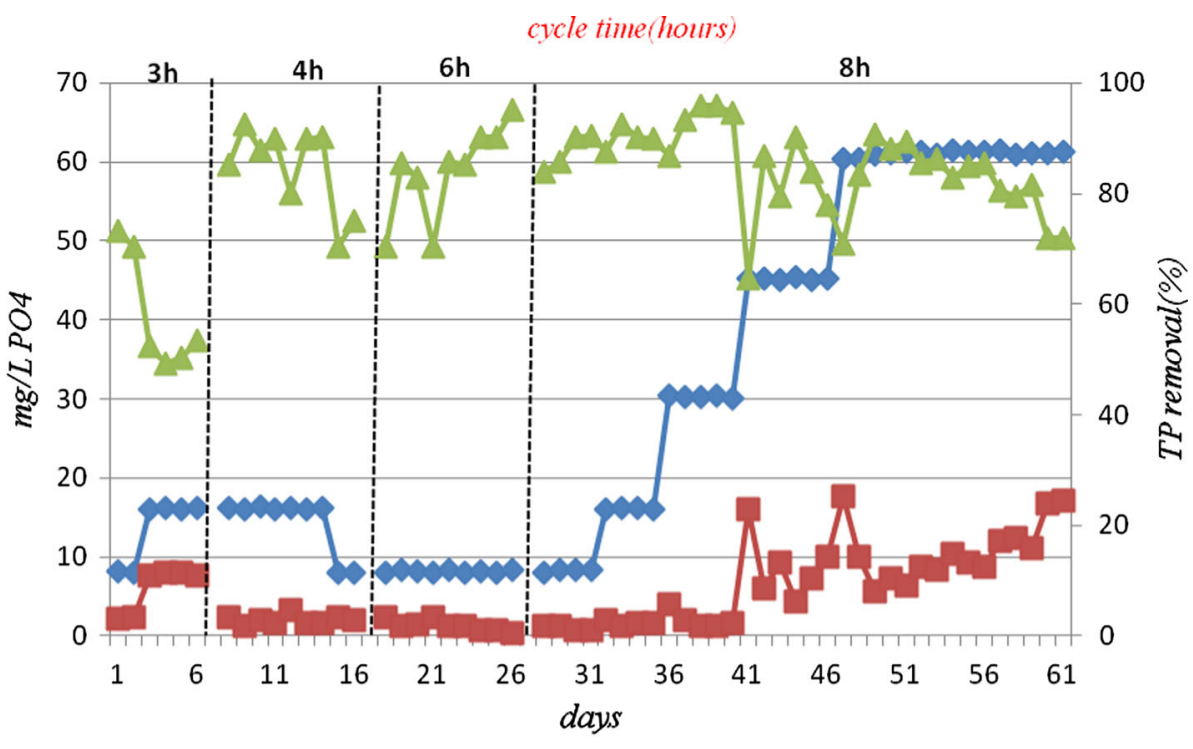

$\multimap$ Input TP $\rightarrow$ Output TP $\longrightarrow$ TP removal(\%) attributed to insufficient settling time (anaerobic). This limits the ability of the PAOs to obtain energy from organic materials to drive the uptake of phosphate in the following aerobic cycles (Yuan et al. 2012). The $100 \%$ increase in settling time (anaerobic) in Phase 2 improved TP removal efficiency. In Phase 2, since conditions in the reactor were permanently anaerobic and the settling time was higher than that in Phase 1, the PAOs were able to gain energy by COD. This was reflected in the increase in TP removal efficiency to $84.5 \%$. At the end of Phase 2, the input TP of $8 \mathrm{mg} / \mathrm{l}$ was similar to that in Phase 3 . However, the removal efficiency was higher in Phase 3. At the beginning of Phase 4 , with inputs of $8 \mathrm{mg} / \mathrm{l} \mathrm{TP}$, the removal efficiency showed no significant increase from Phase 3 . Phase 4 was tested with input TP concentrations of approximately $8,16,30,45$, and $60 \mathrm{mg} / \mathrm{l}$. At input concentrations up to $30 \mathrm{mg} / \mathrm{l}$, the removal efficiency was above $90 \%$. However, at an input concentration of $45 \mathrm{mg} / \mathrm{l}$, the removal efficiency curve fluctuated more than at previous concentrations. At the end of Phase 4, when the input TP value was fixed at $60 \mathrm{mg} / \mathrm{l}$, the level of COD decreased from 1500 to $250 \mathrm{mg} /$ 1. TP removal efficiency was also examined with decreasing amounts of input COD (Fig. 7). As the input COD was reduced, the phosphate removal efficiency remained acceptable until the input COD concentration reached the lowest level. This demonstrates the high removal efficiency of the reactor at very high concentrations of TP, even when input COD levels were very low; reducing the input COD/ $P$ ratio had very little impact on TP removal efficiency. This is an advantage of the new reactor design. The maximum and minimum values of $\mathrm{COD} / \mathrm{P}$ ratio were 25 and 4.1 , respectively, which were consistent with the input

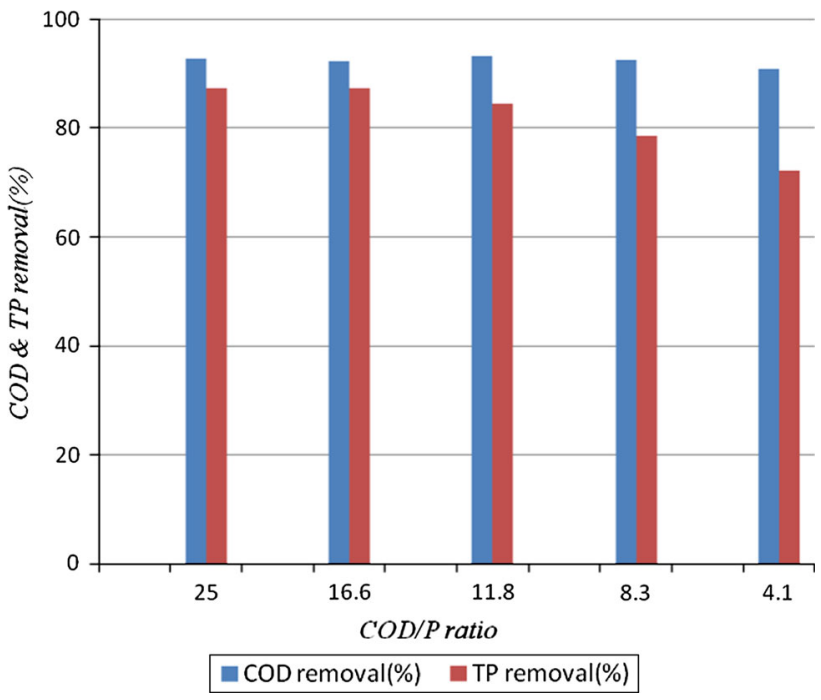

Fig. 7 COD/P ratio against TP and COD removal efficiency in Phase 4

COD of $250 \mathrm{mg} / \mathrm{l}$. Across the entire range of COD/P ratios, COD removal efficiency remained constant at about $92.4 \%$. However, TP removal efficiency decreased from $90 \%$ to approximately $80 \%$ at COD concentrations of $1500-500 \mathrm{mg} / \mathrm{l}$ and to approximately $72 \%$ at COD concentration of $250 \mathrm{mg} / \mathrm{l}$. More than $70 \%$ of $\mathrm{TP}$ was removed at all COD/P ratios, though the best $\mathrm{COD} / \mathrm{P}$ ratios were $25,16.6$, and 11.8 with corresponding removal efficiencies of $87.3,87.2$, and $84.5 \%$, respectively. Previous studies on nutrient removal systems have determined the ratios at which high nutrient removal efficiencies can be achieved. One study of an SBR system with an input COD of $800 \mathrm{mg} / \mathrm{l}$ and $\mathrm{TP}$ of $68 \mathrm{mg} / \mathrm{l}$ demonstrated that at a $\mathrm{COD} / \mathrm{P}$ ratio of $10: 1$, TP removal efficiency was $82 \%$ 
(Broughton et al. 2008). In our reactor, at a COD/P ratio of 11.8 , an input COD of $750 \mathrm{mg} / \mathrm{l}$, and a TP concentration of $60 \mathrm{mg} / \mathrm{l}$, the removal efficiency was $84.5 \%$.

\section{Conclusion}

The novel anaerobic-anoxic/aerobic SBR described in this study had a good COD and nutrient removal efficiency and could successfully remove nitrogen and phosphorus compounds simultaneously. Given the improved nutrient removal when alternating anaerobic-anoxic/aerobic cycles, Phase 4 was identified as the most efficient phase. The key advantages of this new reactor include continuous influent, obviation of the need for sludge or wastewater reuse, lower space requirements through the use of compressed tanks, and the efficient simultaneous removal of phosphate and nitrogen.

Acknowledgments This study was financially supported (No. 92-6646) by the Deputy of Research and Technology of Shiraz University of Medical Sciences.

\section{References}

APHA-AWWA-WEF (1999) Standard methods for the examination of water and wastewater, 20th edn. American Public Health Association/American Water Works Association/Water Environment Federation, Washington

Aslan S, Kapdan IK (2006) Batch kinetics of nitrogen and phosphorus removal from synthetic wastewater by algae. Ecol Eng 28:64-70

Azhdarpoor A, Payam M, Mansoureh D (2014) Removal of phosphate from municipal wastewater using anaerobic/aerobic modified SBR reactor. Int J Environ Sci Toxicol 2(8):152-159

Broughton A, Pratt S, Shilton A (2008) Enhanced biological phosphorus removal for high-strength wastewater with a low rbCOD: P ratio. BioresourTechnol 99:1236-1241

Cassidy D, Belia E (2005) Nitrogen and phosphorus removal from an abattoir wastewater in a SBR with aerobic granular sludge. Water Res 39:4817-4823

Chae S, Shin H (2007) Characteristics of simultaneous organic and nutrient removal in a pilot-scale vertical submerged membrane bioreactor (VSMBR) treating municipal wastewater at various temperatures. Process Biochem 42:193-198

Cui Y, Ding J, Ji S, Peng Y (2014) Start-up of halophilic nitrogen removal via nitrite from hypersaline wastewater by estuarine sediments in sequencing batch reactor. Int J Environ Sci Technol 11:281-292

Drewnowski J, Makinia J (2014) The role of biodegradable particulate and colloidal organic compounds in biological nutrient removal activated sludge systems. Int J Environ Sci Technol 11:1973-1988

Falkowski P, Scholes R, Boyle E, Canadell J, Canfield D, Elser J, Gruber N, Hibbard K, Högberg P, Linder S (2000) The global carbon cycle: a test of our knowledge of earth as a system. Science 290:291-296
Freitas F, Temudo MF, Carvalho G, Oehmen A, Reis MA (2009) Robustness of sludge enriched with short SBR cycles for biological nutrient removal. Bioresour Technol 100:1969-1976

Fu Z, Yang F, An Y, Xue Y (2009a) Simultaneous nitrification and denitrification coupled with phosphorus removal in an modified anoxic/oxic-membrane bioreactor (A/O-MBR). Biochem Eng J 43:191-196

Fu Z, Yang F, Zhou F, Xue Y (2009b) Control of COD/N ratio for nutrient removal in a modified membrane bioreactor (MBR) treating high strength wastewater. Bioresour Technol 100:136-141

Guo J, Yang Q, Peng Y, Yang A, Wang S (2007) Biological nitrogen removal with real-time control using step-feed SBR technology. Enzyme Microb Technol 40:1564-1569

Hu Z, Zhang J, Li S, Xie H, Wang J, Zhang T, Li Y, Zhang H (2010) Effect of aeration rate on the emission of NO in anoxic-aerobic sequencing batch reactors (A/O SBRs). J Biosci Bioeng 109:487-491

Kargi F, Uygur A (2003) Nutrient removal performance of a five-step sequencing batch reactor as a function of wastewater composition. Process Biochem 38:1039-1045

Li B, Irvin S (2007) The comparison of alkalinity and ORP as indicators for nitrification and denitrification in a sequencing batch reactor (SBR). Biochem Eng J 34:248-255

Li M, Nakhla G, Zhu J (2012) Simultaneous carbon and nitrogen removal with enhanced bioparticle circulation in a circulating fluidized bed biofilm reactor. Chem Eng J 181:35-44

Luostarinen S, Luste S, Rintala J (2006) Nitrogen removal from on-site treated anaerobic effluents using intermittently aerated moving bed biofilm reactors at low temperatures. Water Res 40:1607-1615

Metcalf I, Eddy H (2003) Wastewater engineering; treatment and reuse

Morse G, Brett S, Guy J, Lester J (1998) Review: phosphorus removal and recovery technologies. Sci Total Environ 212:69-81

Park W, Nam Y, Lee M, Kim T (2009) Simultaneous nitrification and denitrification in a CEM (cation exchange membrane)-bounded two chamber system. Water Res 43:3820-3826

Rahimi Y, Torabian A, Mehrdadi N, Shahmoradi B (2011) Simultaneous nitrification-denitrification and phosphorus removal in a fixed bed sequencing batch reactor (FBSBR). J Hazard Mater 185:852-857

Renman A, Hylander LD, Renman G (2008) Transformation and removal of nitrogen in reactive bed filter materials designed for on-site wastewater treatment. Ecol Eng 34:207-214

Sibag M, Kim S (2012) Nitrification denitrification enhanced biological phosphorous removal (NDEBPR) occurs in a labscale alternating hypoxic/oxic membrane bioreactor. Bioresour Technol 104:173-180

Wang L, Li Y, Chen P, Min M, Chen Y, Zhu J, Ruan R (2010) Anaerobic digested dairy manure as a nutrient supplement for cultivation of oil-rich green microalgae Chlorella sp. Bioresour Technol 101:2623-2628

Wei Y, Ji M, Li R, Qin F (2012) Organic and nitrogen removal from landfill leachate in aerobic granular sludge sequencing batch reactors. Waste Manag 32:448-455

Wu P, Ji X, Song X, Shen Y (2014) Mechanism of efficient nutrient removal and microbial analysis of a combined anaerobic baffled reactor-membrane bioreactor process. Int J Environ Sci Technol 11:1611-1618

Yuan Z, Pratt S, Batstone D (2012) Phosphorus recovery from wastewater through microbial processes. Curr Opin Biotechnol 23:878-883

Zhou Y, Lim M, Harjono S, Ng W (2012) Nitrous oxide emission by denitrifying phosphorus removal culture using polyhydroxyalkanoates as carbon source. J Environ Sci 24:1616-1623 